\title{
Internalisasi Nilai Tawakal pada Santri di Pondok Pesantren Badrul Ulum Al-Islami
}

\author{
Pupu Fakhrurrozi,* Aceng Kosasih, Fahrudin \\ Universitas Pendidikan Indonesia \\ e-mail:fakhrurrozi1992@gmail.com
}

\begin{abstract}
This research was conducted in PondokPesantrenBadrulUlum Al-Islami as salaf Islamic boarding school which was founded in 1918 and still exist until now. The method used in this research is descriptive method with qualitative approach and supported by literature study. The result obtained from this research are: The goal of internalization of tawakal value with zikryawakil is for clearing the soul (saffatasraruhu). Internalization process of tawakal value among others applied in activity of congregation of zikr, learning activity, and activity daily. The result of internalization of the value of tawakal is that the person will have a happy feeling. The obstacle are not yet thoroughly awareness of the internalization of tawakal value, the existence of takhassus student under the age of high scholl, and the lack of cohesiveness amongst students in order to help maximazepondokpesantren's program.
\end{abstract}

Keyword: Internalization, value, tawakal, PondokPesantren 


\section{Pendahuluan}

Dekadensi moral menjadi satu hal yang hangat diperbincangkan saat ini. Hal ini disebabkan fenomena dekadensi moral selalu disuguhkan dengan begitu dahsyat. Dalam rusaknya akhlak, dekadensi moral, hancurnya tatanan peradaban, hilangnya perasaan damai, timbulnya kecurigaan dan ketidakpercayaan yang berlebihan, penindasan yang kuat kepada yang lemah, meluasnya pembunuhan karakter, berantakan tata nilai kehidupan, korupsi yang merajalela, hilangnya rasa hormat kepada sesama, terjerumus pada lubang kehinaan, lalainya ketaatan beribadah hal ini diindikasikan akibat rusaknya sistem pendidikan (Sauri, 2013:1).

Pendidikan di Indonesia memiliki ketidakseimbangan antara pendidikan akademik, pendidikan akhlak/pendidikan nilai dan pendidikan keterampilan. Dari sudut pendidikan nilai, sebagaimana yang dikehendaki oleh tujuan pendidikan nasional, maka pendidikan di Indonesia dapat dikatakan gagal atau kurang berhasil. Fenomena kegagalan ini misalnya dapat dilihat dari produk pendidikan yang menghasilkan generasi yang kurang hormat pada guru/dosen, orang tua, sering terjadi tawuran, pergaulan bebas, gaya hidup hedonisme, kebarat-baratan (meninggalkan budaya bangsa) dalam beberapa hal seperti dalam fashion, musik, makanan dan lain-lainnya (Fahrudin, 2013:6). Walaupun Indonesia merupakan negara dengan penduduk muslim terbanyak di dunia, pemahaman mengenai makrifat kepada Allah SWT belum tertanam di dalam jiwa setiap muslim Indonesia. Padahal makrifat kepada Allah akan menyucikan jiwa dari sifat buruk, seperti dendam, sum'ah (ingin didengar), riya ' (ingin dilihat), hubb al-jāb (gila kedudukan), hubb al-māl (gila harta), dan sifat buruk lainnya. Kesucian jiwa akan mendorong seseorang untuk beramal saleh sedangkan amal saleh akan menghapus dosa-dosa, dan kemudian Allah akan menggantinya dengan pahala yang berlipat ganda (Affandi, 2008:19).

Bentuk untuk mencapai kesucian jiwa yang akan mendorong seseorang untuk beramal saleh diperlukan usaha diantaranya adalah selalu bertawakal kepada Allah SWT. Tawakal merupakan salah satu hasil dari iman dan buah dari makrifat. Sejauh mana seorang hamba mengenal Allah SWT dan sifat-sifat-Nya, maka sejauh itu pulalah tawakalnya kepada-Nya. Sesungguhnya yang bertawakal kepada Allah SWT hanyalah orang yang tidak melihat adanya pelaku selain Dia. Orang yang bertawakal kepada Allah adalah orang yang bangga dengan-Nya, tidak merasa hina kecuali di hadapan-Nya, percaya sepenuhnya dengan-Nya, dan tidak meminta sesuatu kecuali dari-Nya. Kaum 
sufi berkata "Buruk bagi seorang murìd, meminta sesuatu kepada seorang hamba, padahal dia menemukan semua apa yang diinginkannya pada Tuhannya"(Isa, 2005:263).

Pesantren Badrul Ulum ini menerapkan sistem pengajaran tradisional pengajian Alquran, Hadis, kitab klasik (kitab kuning) termasuk kitab al-hikām karya syekh Ibn Ațāillah, dan mengamalkan żikir $Y \bar{a}$ Wakìl. Żikir tersebut diamalkan oleh santri-santri senior setiap malam di masjid pesantren dengan sistem jadwal atau bergantian setiap malamnya. Diamalkan oleh seluruh santri pada setiap malam minggu secara berjamaah. Amalan żikir ini tidak hanya diamalkan oleh santri saja, tetapi juga oleh masyarakat sekitar pesantren, termasuk para alumni, sehingga baik antara ikatan pesantren dengan alumni maupun masyarakat pada umumnya masih terus terjalin. Hal tersebut membuat peneliti tertarik untuk mengadakan penelitian di pondok pesantren tersebut untuk membahas internalisasi nilai tawakal pada santri di Pondok Pesantren Badrul Ulum Al-Islami.

\section{Metode Penelitian}

Metode yang digunakan dalam penelitian ini yaitu metode deskriptif dengan pendekatan kualitatif serta ditunjang oleh studi kepustakaan. Menurut Satori (2012:22) penelitian kualitatif adalah penelitian yang menekankan pada quality atau hal yang terpenting dari sifat suatu barang/jasa. Desain yang digunakan adalah desain case study yang bersifat deskriptif, karena bertujuan memaparkan internalisasi nilai tawakal pada santri di Pondok Pesantren Badrul Ulum Al-Islami

Teknik yang digunakan untuk mengumpulkan data yaitu wawancara, pengamatan langsung, dan studi dokumentasi. Teknik analisis data menggunakan teknik deskriptif interpretatif. Menurut Sugiyono (2011:309) dalam penelitian kualitatif, pengumpulan data dilakukan pada natural setting (kondisi yang alamiah), sumber data primer, dan teknik pengumpulan data lebih banyak pada observasi berperan serta (participant observation), wawancara mendalam (in depth interview) dan dokumentasi.

\section{Internalisasi Nilai Tawakal Pada Santri di Pondok Pesantren Badrul Ulum Al-}

\section{Islami Pacet - Kabupaten Bandung}

Internalisasi nilai menurut Chabib Thoha dalam (Nashihin, 2015:3) yaitu merupakan teknik dalam pendidikan nilai yang sasarannya adalah sampai pada pemilikan nilai yang menyatu dalam kepribadian dan perilaku peserta didik. Internalisasi diartikan 
sebagai proses penanaman nilai kedalam jiwa seseorang sehingga nilai tersebut tercermin pada sikap dan prilaku yang ditampakkan dalam kehidupan sehari-hari (menyatu dengan pribadi) (Utomo, 2016:95). Dengan memperbanyak zikir yā wakìl ini harapannya agar nilai ketawakalan dapat terinternalisasi dalam diri setiap santri.

Syekh Abu Nashr as-Sarraj - rahāmahullāh- (2002:105) mengatakan bahwa tawakal adalah kedudukan spiritual yang mulia. Allah telah memerintahkan untuk selalu bertawakal dan Dia menjadikannya selalu berbarengan dengan iman. Sebagaimana firman-Nya:

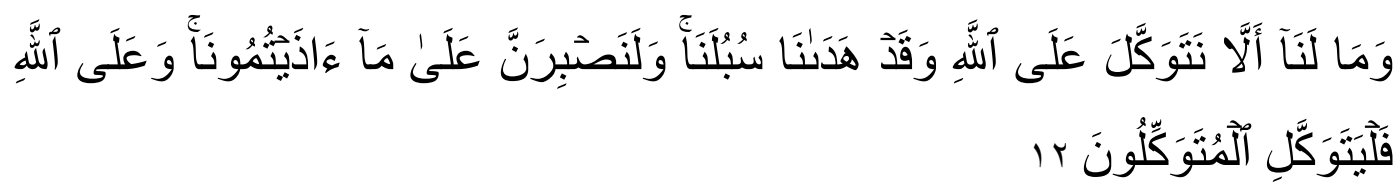

Artinya: "Mengapa kami tidak akan bertawakkal kepada Allah padahal Dia telah menunjukkan jalan kepada kami, dan kami sungguh-sungguh akan bersabar terhadap gangguan-gangguan yang kamu lakukan kepada kami. Dan hanya kepada Allah saja orang-orang yang bertawakkal itu, berserah diri” (Q.S. Ibrahim [14]: 12).

Kaum sufi telah merumuskan teori-teori tentang jalan menuju Allah, yakni menuju suatu tahap ma'rifat (mengenal Allah dengan hati). Potensi untuk memperoleh ma'rifat sebenarnya telah ada pada manusia. Untuk memperolehnya, hati mempunyai fungsi yang esensial, hati merupakan tempat kedatangan kashf dan ilhām. Dalam dunia tasawuf, hati merupakan pengetahuan tentang hakikat, termasuk di dalamnya adalah hakikat ma'rifat. Hati yang dapat memperoleh ma 'rifat adalah hati yang telah suci dari berbagai akhlak tercela yang sering dilakukan oleh manusia. Hati menjadi sarana untuk memperoleh ma 'rifat. Hatilah yang mampu mengetahui hakikat pengetahuan, karena hati dibekali potensi untuk berinteraksi dengan Tuhan. Ini mengisyaratkan bahwa ma 'rifat tidak spontan dimiliki sembarang orang, melainkan hanya dimiliki orang-orang yang telah melakukan upaya-upaya untuk memperjuangkannya. Di samping melalui tahapan maqāmat dan ahwāl, untuk memperoleh ma'rifat seseorang harus melalui upaya-upaya tertentu, seperti riyā dā (Hakam, 2014:147).

Diantara riyā $d a \bar{h}$ untuk menuju tahap ma'rifat adalah zikir. Asal zikir adalah ashshafa, artinya bersih dan hening. Wadahnya adalah al-wafa artinya menyempurnakan dan syaratnya adalah al-hudhur, artinya hadir hati sepenuhnya. Hamparannya adalah amal saleh, dan khasiatnya adalah pembukaan dari Tuhan Al-Aziz Ar-Rahman. Menurut 
bahasa, zikir artinya ingat atau sebut. Kalau dalam pengertian ibadah, zikir berarti suatu amal yang disebut berzikir. Jadi, zikir Allah atau dzikrullah artinya ingat kepada Allah atau menyebut Allah. Di dalam Alquran tidak sedikit ayat-ayat yang menyuruh kita mengingat Allah atau menganjurkan orang berzikir dan menyatakan keutamaan zikir Allah. Demikian pula hadis Nabi, atsar sahabat dan tabi'in banyak sekali menyebutkan fadhilah zikir (Abdullah, 2007:82).

Pesantren merupakan lembaga pendidikan yang bertujuan untuk taffaquh fiddin (memahami agama) dan membentuk moralitas umat melalui pendidikan. Sampai sekarang, pesantren pada umumnya bertujuan untuk belajar agama dan mencetak pribadi muslim yang kaffah yang melaksanakan ajaran Islām secara konsisten dalam kehidupan sehari-hari. Tujuan taffaquh fiddin dan mencetak kepribadian muslim yang kaffah dalam melaksanakan ajaran Islām didasarkan kepada tuntutan Alquran dan sunaћ Nabi SAW. Dimana nabi merupakan top model dan guru imajiner bagi pesantren. Tujuan ini adalah tujuan pokok dalam setiap pesantren yang merupakan lembaga pendidikan Islām tradisional yang teguh menjaga tradisi ulama salaf al shalih dan walisongo yang diyakini bersumber dari Rasūlullāh SAW. Dengan ini maka Islām akan bertahan dan berkembang dalam masyarakat, khususnya di Indonesia. Adapun mengenai tujuan-tujuan khusus, masing-masing pesantren juga mempunyai tujuan khusus yang tergantung dengan pengasuhnya (Suharto, 2011:11).

Tujuan internalisasi nilai tawakal pada santri di Pondok Pesantren Badrul Ulum AlIslami ditekankan pada amalan zikir yā wakìl, agar bertawakal, karena tawakal itu adalah derajat keyakinan paling tinggi. Tujuan yā wakìl agar jernih hati (Ṣaffat asrāruhu) karena setelah hati jernih seseorang akan sampai ke hadirat Ilahiyah. Tawakal itu menyerahkan segala urusan kepada Allah SWT setelah kita berusaha semaksimal mungkin. Perjalanan yā wakīl ini merupakan perjalanan melalui jamalullah (keindahan Allah, ke-rahman-an Allah). Maka pada amalan yā wakìl harus merasa bahagia. Seseorang yang mengamalkan zikir ini harus mengingat berbagai nikmat Allah, sudah diurus oleh Allah, diciptakan oleh Allah, diberi rezeki oleh Allah, dan nikmat-nikmat lainnya.

Tujuan internalisasi nilai tawakal pada santri Pondok Pesantren Badrul Ulum AlIslami ini sudah sangat sejalan dengan tujuan pendidikan Islam sendiri. Tujuan pendidikan Islām menurut Abu Ahmadi (Ramayulis, 2011:134-143) bahwa tahap-tahap tujuan pendidikan Islām meliputi tujuan tertinggi/terakhir, tujuan umum, tujuan khusus dan sementara.Tujuan pendidikan yang tertinggi dan terakhir ini pada akhirnya sesuai dengan 
tujuan hidup manusia, dan peranannya sebagai makhluk ciptaan Allah. Dengan demikian, indikator dari insan kamil tersebut adalah menjadi hamba Allah, tujuan ini sejalan dengan tujuan hidup dan penciptaan manusia yaitu semata-mata untuk beribadah kepada Allāh. Dalam hal ini pendidikan harus memungkinkan manusia memahami dan menghayati tentang Tuhannya, mengantarkan subjek didik menjadi khalīfăh Allāh fi al-'Ard, yang mampu memakmurkan bumi dan melestarikannya dan lebih jauh lagi, mewujudkan rahmat bagi alam sekitarnya dan untuk memperoleh kesejahteraan kebahagiaan hidup di dunia dan akhirat. Ciri-ciri insan kamil menurut (Nata, 2003:264-267) adalah sebagai berikut, 1) berfungsi akalnya secara maksimal; 2) berfungsi intuisinya; 3) mampu menciptakan budaya; 4) menghiasi diri dengan sifat-sifat ketuhanan; 4) berakhlak mulia; 5) berjiwa seimbang

Supaya tawakal, maka amal (zikir) nya adalah yā wakìl, tawakal itu adalah orang yang berpasrah diri secara total kepada Allah, untuk mencapai itu maka harus (mengamalkan) yā wakìl yakni Allah wahai dzat yang mengurus kita, wahai dzat yang menerima penyerahan kita. Sebagaimana terdapat dalam al-Qur`an surat Al-Thalaq [65] $: 3$

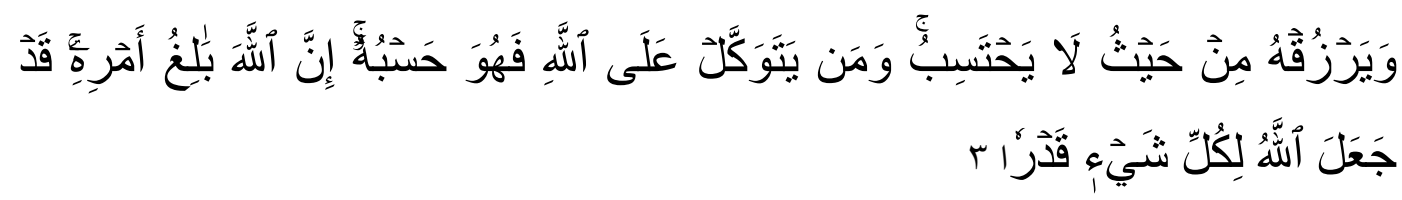

Artinya: "Hai Nabi, apabila kamu menceraikan isteri-isterimu maka hendaklah kamu ceraikan mereka pada waktu mereka dapat (menghadapi) iddahnya (yang wajar) dan hitunglah waktu iddah itu serta bertakwalah kepada Allah Tuhanmu. Janganlah kamu keluarkan mereka dari rumah mereka dan janganlah mereka (diizinkan) ke luar kecuali mereka mengerjakan perbuatan keji yang terang. Itulah hukum-hukum Allah dan barangsiapa yang melanggar hukum-hukum Allah, maka sesungguhnya dia telah berbuat zalim terhadap dirinya sendiri. Kamu tidak mengetahui barangkali Allah mengadakan sesudah itu sesuatu hal yang baru."

Proses internalisasi nilai tawakal pada santri di Pondok Pesantren Badrul Ulum Al-Islami diantaranya diterapkan dalam beberapa hal. Diantaranya aktivitas dzikir berjamaah dilakukan setiap Sabtu Kliwon berbarengan dengan kajian kitab Hikam Syaikh Ibn At-Thaillah. Zikir berjamaah dilakukan setiap bakda salat, sementara zikir yā wakīl pada malam Minggu, dan hari Jumat. Adapun zikir yang dilakukan pada waktu dini hari 
menjelang subuh merupakan rutinitas bagi santri senior, karena waktu tersebut merupakan waktu terbukanya hijab antara seorang 'abdi/hamba dengan Allah SWT. Untuk seluruh santri, tidak diwajibkan mengamalkan amalan yā wakīl ini. Santri hanya difokuskan untuk mengaji saja, amalan dzikir yā wakìl ini hanya untuk memantapkan hati saja. Selain dari amalan zikir, di pesantren Badrul Ulum juga diajarkan kitab-kitab tasawuf dan juga kitabkitab tauhid seperti minhah saniyah, bugyatul auliya, al-hikam, dan lain sebagainya. Keilmuan masalah hati, amalnya seperti berdzikir bersama, berjamaah dalam beribadah. Sanad zikir yā wakīl ini dari Syaikh Khalil Bangkalan, Syaikh Abi Syamsiddin, Syaikh Muhammad Bahauddin al-Uwaisy, Syakih ‘Abdul Qadir al-Jailani, Syaikh Abi Yazid alBustami, kesananya dari Imam Al-Ghazali.

Al-Qusyairi berkata:

"Tempat tawakal adalah hati. Dan gerakan dengan anggota tubuh tidak bertentangan dengan tawakal dalam hati, setelah seorang hamba yakin bahwa takdir adalah kehendak Allah. Jika sesuatu sulit, maka itu adalah karena takdir-Nya. Dan jika dia sesuai (dengan keinginan kita), maka itu karena kemudahan-Nya."

\section{Al-Ghazali berkata:}

"Orang-orang yang bodoh menyangka bahwa syarat tawakal adalah meninggalkan usaha dan pengobatan, serta menyerah pada semua yang menghancurkan. Hal ini merupakan kesalahan, karena semua itu diharamkan oleh syariat. Syariat telah memuji tawakal dan mengharuskannya. Maka bagaimana bisa tawakal diterima jika dia berkaitan dengan hal-hal yang dilarang?"

Para sufi telah menunjukkan sālik kepada sisi hati yang dalam, yaitu bahwa dalam setiap pekerjaan dia harus berusaha, tanpa bergantung pada usaha tersebut atau mencondongkan hati kepadanya.

\section{Qadhi Iyadh berkata:}

"Para sufi selalu menekankan pentingnya berusaha. Akan tetapi, mereka tidak membenarkan jika tawakal dibarengi dengan keberpalingan dan ketundukan terhadap usaha. Usaha tersebut merupakan sunnah Allah dan hikmah-Nya. Dan seseorang harus yakin bahwa itu tidak dapat memberi manfaat dan menolak mudarat. Akan tetapi, semuanya bersumber dari Allah"(Isa, 2005:262-263).

Hasil internalisasi nilai tawakal pada santri di Pondok Pesantren Badrul Ulum Al-Islami terlihat dalam beberapa hal. Diantaranya orang yang sudah bertawakal akan mempunyai perasaan bahagia, karena tawakal adalah masalah hati, jadi orang yang sudah 
mengamalkan yā wakìl ini akan tenang hatinya. Perubahan dari sebelum dan setelah amalan zikir yā wakīl setiap orang bisa berbeda-beda. Santri di Pesantren Badrul Ulum juga ada yang mempunyai beberapa kelebihan, diantaranya ada yang ahli dalam bidang kaligrafi, menguasai ilmu nahwu sharaf, ada yang ahli dalam bidang grafiti, ada yang ahli dalam hal pertanian, ada santri yang ahli di bidang bangunan, ada santri yang kuat hafalannya, rajin dalam belajar dan mengaji, serta ada yang ahli di bidang qiraat. Pondok Pesantren Badrul Ulum Al-Islami secara administrasi formal telah berjalan beberapa tahun yang lalu, dan telah meluluskan beberapa angkatan dengan cukup memuaskan, baik dari sisi pembelajaran atau dari akhlak yang ditunjukan oleh santri. Para santri berasal dari beberapa kota di Jawa Barat, khususnya dari lingkungan sekitar bahkan ada dari luar Jawa Barat (Lampung, Jawa Timur, Medan). Dari tahun ada juga para santri yang telah meraih beberapa kejuaraan khususnya dalam eventMusabaqah Tilawatil Quran (MTQ), baik pada tingkat lokal, nasional maupun internasional.

Ibnu Qayyim dalam (Mulyana, 2015:18-19) memberikan ketentuan-ketentuan aspek tawakal sebagai berikut:

1. Memiliki keyakinan yang benar tentang kekuasaan dan kehendak Allah SWT.

2. Mengetahui hukum sebab akibat akan urusan yang dikerjakan.

3. Memperkuat kalbu dengan tauhid.

4. Menyandarkan kalbu kepada Allah dan merasa senang di sisinya.

5. Memiliki prasangka yang baik kepada Allah.

6. Menyerahkan kalbu sepenuhnya kepada-Nya dan menghalau apa saja yang merintangi.

7. Pasrah atau menyerahkan semua urusan kepada-Nya.

Hambatan internalisasi nilai tawakal pada santri di Pondok Pesantren Badrul Ulum Al-Islami diantaranya adalah belum begitu menyeluruhnya kesadaran mengenai internalisasi nilai tawakal. Jika ada seseorang yang sudah menerima ijazah zikir tetapi tidak mengamalkan zikir tersebut, maka orang tersebut bisa dikategorikan turun derajat, kalau sudah bernazar berarti berdosa. Hambatan lainnya adalah ada beberapa santri yang masih berusia sekolah seperti dari mulai tingkat SD, SMP dan SMA yang tidak melanjutkan sekolahnya. Dikhawatirkan pemahaman terhadap nilai tawakal pun kurang optimal. Kemudian ada juga hambatan lain yakni mengenai administrasi data-data kepesantrenan. Masih kurangnya kekompakan sesama kepengurusan santri dalam rangka membantu memaksimalkan program kepesantrenan, baik penerapan punishment terhadap 
santri yang melanggar peraturan maupun ketegasan dalam setiap program internalisasi khususnya internalisasi nilai tawakal.

Hambatan dari internalisasi nilai tawakal ini sebenarnya sangat banyak. Namun, di Pesantren Badrul Ulum sendiri karena merupakan pesantren salaf yang juga mengadakan sekolah. Maka hambatan yang dirasa pun tidak hanya dari sisi klasiknya saja tetapi juga dari dampak modernisasi global. Maka dari itu, di pesantren Badrul Ulum ini tetap diadakan pengupayaan untuk menguatkan keimanan dan meningkatkan keilmuan.

Allah menciptakan manusia dalam keadaan fitrah dalam arti berpotensi, yaitu kelengkapan yang diberikan pada saat dilahirkan ke dunia. Potensi yang dimiliki manusia tersebut dapat dikelompokkan kepada dua hal, yaitu potensi fisik dan potensi ruhaniah. Potensi fisik adalah tubuh manusia. Proses kejadian manusia dijelaskan dalam Alquran dan had̄̄s. Diantara ayat-ayat Alquran yang mengungkapkan penciptaan manusia antara lain dalam surat al-Mu’minūn [23] : 12-14 yang berbunyi:

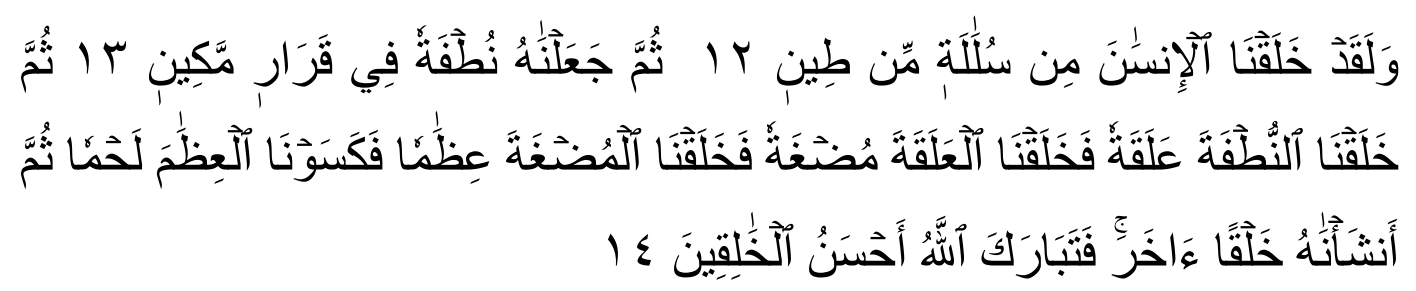

Artinya: "Dan sesungguhnya Kami telah menciptakan manusia dari suatu saripati (berasal) dari tanah. Kemudian Kami jadikan saripati itu air mani (yang disimpan) dalam tempat yang kokoh (rahim). Kemudian air mani itu Kami jadikan segumpal darah, lalu segumpal darah itu Kami jadikan segumpal daging, dan segumpal daging itu Kami jadikan tulang belulang, lalu tulang belulang itu Kami bungkus dengan daging. Kemudian Kami jadikan dia makhluk yang (berbentuk) lain. Maka Maha sucilah Allah, Pencipta Yang Paling Baik”'(Q.S. al-Mu’minūn [23]: 12-14)

Ayat-ayat yang menerangkan tentang penciptaan manusia lebih diperjelas lagi oleh Rasulullah SAW, antara lain:

"Sesungguhnya setiap kalian dikumpulkan kejadiannya dalam perut ibunya 40 hari dalam bentuk nutfah, kemudian dalam bentuk alaqah seperti itu (40 hari) lalu dalam bentuk mudgah seperti itu (40 hari), kemudian diutus Malaikat kepadanya lalu Malaikat itu meniupkan ruh ke dalam tubuhnya." (H.R. Bukhari dan Muslim)

| Volume. 3, No. 2, Juli-Desember 2018 
Sedangkan potensi ruhaniah adalah akal, qalbu dan nafsu. Akal berasal dari bahasa Arab, yaitu dari kata jadian 'Aqala Ya 'qilu-Aqlan, yang secara etimologi berarti mengikat atau menahan, mengerti dan membedakan(Kosasih, 2009:98-99).

\section{Kesimpulan}

Kesimpulan dari penelitian ini yakni tujuan internalisasi nilai tawakal pada santri di Pesantren Badrul Ulum ditekankan pada amalan zikir yā wakīl, agar bertawakal, karena tawakal itu adalah derajat keyakinan paling tinggi. Tujuan yā wakìl adalah agar hati jernih (Ṣaffat asrāruhu) karena setelah hati jernih seseorang akan sampai ke hadirat Ilahiyah. Proses internalisasi nilai tawakal pada santri di Pesantren Badrul Ulum diantaranya diterapkan dalam beberapa hal, yakni aktivitas zikir berjamaah, kegiatan pengajian, dan aktivitas keseharian. Hasil internalisasi nilai tawakal pada santri di Pesantren Badrul Ulum adalah bahwa orang yang sudah bertawakal akan mempunyai perasaan bahagia, karena tawakal adalah masalah hati, jadi orang yang sudah mengamalkan yā wakīl ini akan tenang hatinya. Hambatan internalisasi nilai tawakal pada santri di Pondok Pesantren Badrul Ulum diantaranya adalah belum begitu menyeluruhnya kesadaran mengenai internalisasi nilai tawakal, adanya santri takhassus di bawah usia SMA, serta kurangnya kekompakan sesama kepengurusan santri dalam rangka membantu memaksimalkan program kepesantrenan.

\section{Daftar Pustaka}

Abdullah, M. . (2007). Dzikir dan Tasawuf. Solo: Qaula.

Affandi, C. (2008). La Tahzan Innallaha Ma'ana Bersama Allah di Setiap Tempat dan Waktu. Bandung: Mizania.

As-Sarraj, A. (2002). Al-Luma' Rujukan Lengkap Ilmu Tasawuf, Al-Luma Lajnah Nasyr at-Turats ash-Shufi. (Wasmukan \& S. Rahman, Eds.). Surabaya: Risalah Gusti.

Fahrudin. (2013). Implementasi Pendidikan Nilai Keimanan Berbasis Tasawuf Sebagai Upaya Membentuk Karakter Manusia 'Arifun Billah di SMA Pondok Modern Sumber Daya At-Taqwa (POMOSDA) Tanjung Anom-Nganjuk-Jawa Timur. Universitas Pendidikan Indonesia. 
Hakam, A. (2014). K.H. Hasyim Asy'ari dan Urgensi Riyadah dalam Tasawuf Akhlaqi. Teosofi, 4(1).

Isa, S. (2005a). Hakekat Tasawuf (Haqāiq at-Tashawwuf). Jakarta: Qisthi Press.

Isa, S. (2005b). Hakekat Tasawuf (Haqāiq at-Tashawwuf). (K. A. Harahap, Ed.). Jakarta: Qisthi Press.

Kosasih, A. (2009). Konsep Manusia Utuh dalam Pendidikan Umum. Ta'lim Jurnal Pendidikan Agama Islam, 7(2).

Mulyana, A. (2015). Tawakal dan Kecemasan Mahasiswa pada Mata Kuliah Praktikum. Psympathic, Jurnal Ilmiah Psikologi, 2(1).

Nashihin. (2015). Internalisasi Nilai-nilai Agama Islam dalam Pembinaan Akhlak Mulia. Jurnal Ummul Qura, V(1).

Nata, A. (2003). Akhlak Tasawuf. Jakarta: PT Raja Grafindo Persada.

Ramayulis. (2011). Ilmu Pendidikan Islam. Jakarta: Kalam Mulia.

Satori, D. (2012). Metodologi Penelitian Kualitatif. Bandung: Alfabeta.

Sauri, S. (2013). Bulan Rabiul Awwal Penuh Makna Keteladanan. Buletin Al Furqan.

Sugiyono. (2011). Metode Penelitian Pendidikan (Pendekatan Kuantitatif, Kualitatif, dan $R \$ D)$. Bandung: Alfabeta.

Suharto. (2011). Dari Pesantren Untuk Umat. Surabaya: Imtiyaz.

Utomo, E. . (2016). Internalisasi Nilai-Nilai Karakter dalam Pembelajaran IPS pada Siswa SMP Negeri Model Terpadu Bojonegoro. Metafora, 2(2), 91-104. 